\title{
Birth Weight Deviation and Early Postnatal Growth Are Related to Optic Nerve Morphology at School Age in Children Born Preterm
}

\author{
MARGARETA H. WIKSTRAND, ANNA-LENA HÅRD, AIMON NIKLASSON, AND ANN HELLSTRÖM
}

Departments of Ophthalmology [M.H.W., A.-L.H., A.H.] and Pediatrics [A.N.], University of Gothenburg, 40530 Gothenburg, Sweden

\begin{abstract}
The aim of this study was to evaluate the influence of early and later postnatal growth variables on optic disc morphology in children $(n=53)$ born at gestational age $<32$ wk. On fundus photographs taken at a median age of $5.4 \mathrm{y}$, the optic discs were evaluated using digital image analysis and compared with those of a control group $(n=203)$. The results were analyzed in relation to gestational age, birth weight (BW) SD score (SDS), IGF-1 weight at postmenstrual age $32 \mathrm{wk}$ (SDS), and weight, length, and head circumference (SDS) at follow-up. The preterm children's optic disc and neuronal rim areas were smaller than in the control group. Low BW (SDS) and weight at wk 32 (SDS) were associated with larger area of the optic cup and reduced neuronal rim area. Preterm children with known brain lesions $(n=6)$ had significantly larger cups than preterm children without known brain lesions. The association found between both low $\mathrm{BW}$ and poor early growth and later reduced neuronal tissue of the optic nerve indicate that early weight gain is important for neural development in preterm children. (Pediatr Res 67: 325-329, 2010)
\end{abstract}

$\mathrm{T}^{\mathrm{s}}$ he prematurely born infant is prone to neuronal and vascular tissue insults when born into extrauterine life during a sensitive period of maturation of the CNS, when synaptogenesis, apoptosis, myelination, reorganization, and vasculogenesis/angiogenesis take place.

Preterm birth carries a high risk for peri- or postnatal brain lesions, and brain damage is a common cause of visual impairment in children in developed countries (1). White matter damage (WMD) occurs in 30 to $50 \%$ of children born before 30-wk gestational age (GA) $(2,3)$ or with a birth weight (BW) $<1500 \mathrm{~g}$ (4). Periventricular leucomalacia (PVL) is frequent in children born preterm and may cause visual impairment (5) and/or cerebral palsy (6). Intraventricular hemorrhage (IVH) has been reported to occur in $61 \%$ of infants born before 34-wk GA (7). It may be associated with variable degrees of ischemia and WMD and can cause hydrocephalus that may further impair vision.

Preterm birth as well as poor intrauterine ${ }^{1}$ growth in fullterm babies has been shown to be associated with subnormal disc and neuronal rim areas of the optic nerve and with an abnormal retinal vessel pattern (8-12). McLoone et al. (7) reported, in a group of preterm infants with IVH, a trend

Received May 22, 2009; accepted November 7, 2009.

Correspondence: Margareta Hök Wikstrand, M.D., Department of Ophthalmology, Sahlgrenska University Hospital, Mölndal, 43180 Mölndal, Sweden; e-mail: margareta. hok-wikstrand@vgregion.se

Supported by Göteborgs Läkaresällskap, the Swedish Research Council, the "Föreningen De Blindas Vänner," the "Wilhem och Martina Lundgrens Vetenskapsfond." toward smaller optic disc, neuronal rim, and cup area with increasing severity of IVH, but only children with IVH grade IV were reported to have a significantly increased incidence of optic nerve hypoplasia. They found no association between the optic disc morphology and timing of brain injury. Large cups in normal-sized optic discs have been reported in preterm children with PVL born at GA <37 wk (12). In another study, children with PVL had a significantly smaller disc area if the damage was estimated to have occurred before 28 postmenstrual weeks and a larger cup of the optic disc and a smaller neuronal rim area if the cerebral WMD was estimated to have occurred later than 28 postmenstrual weeks (13). Children operated on for hydrocephalus have been reported to have smaller optic disc and neuronal rim areas than controls (14).

IGF-1 is essential for normal vascularization of the retina (15), and low levels of postnatal serum levels of IGF-1 are associated with development of retinopathy of prematurity (ROP) (16) and head growth deficits (17). IGF-1 is a growth factor important for the development of the CNS, promoting proliferation, maturation, and differentiation of neural stem cells and neuronal and oligodendrocyte precursors (18).

The aim of this study was to compare optic disc morphology in preterm infants with that of a control group and to evaluate the influence of GA, BW and postnatal growth variables on the ocular fundus morphology.

\section{MATERIAL AND METHODS}

Study group. The subjects were part of a larger cohort of children born between December 1999 and April 2002 with a GA of <32 wk, who were previously examined with regard to postnatal serum levels of IGF-1 in relation to ROP. Of the initial study group $(n=70)$, which is described in detail elsewhere (16), 66 were examined regarding ophthalmologic outcome at school age. For inclusion in the ocular fundus analysis, fundus photographs taken at the time of the eye examination had to be of satisfactory quality with the optic nerve head well centered (within half a disc size off center). Fifty-three children ( 24 boys and 29 girls) had fundus photographs, which allowed evaluation of the optic nerve head and were included in the study. All children were examined with ophthalmoscopy. Median corrected age at examination was $5.4 \mathrm{y}$ (range $4.8-6.1$ ). The median GA at birth was $27.1 \mathrm{wk}$ (range 23.4-31.1), and the median BW was $970 \mathrm{~g}$ (range 530-2015). Nine infants $(17.0 \%)$ were born small for gestational age (SGA) [BW SD score $(\mathrm{SDS})<-2$ ] (range -5.0 to -2.3$)$ and at $32 \mathrm{wk}, 34(64 \%)$ infants had weight SDS $<-2$. ROP had been found in 34 infants and nine developed ROP stage 3 , of whom four children were treated with laser ablation. Six children had

\footnotetext{
Abbreviations: BW, birth weight; GA, gestational age; IVH, intraventricular hemorrhage; PVL, periventricular leucomalacia; ROP, retinopathy of prematurity; SGA, small for gestational age; WMD, white matter damage
} 
Table 1. Characteristics at base line

\begin{tabular}{lc}
\hline \multicolumn{1}{c}{ Characteristics } & $\mathrm{n}=53$ \\
\hline Neonatal & $27.6(2.08)$ \\
GA weeks, mean (SD) & $27.1(23.4$ to 31.1) \\
median (range) & $1063(343)$ \\
BW g, mean (SD) & $-0.9(-5.0$ to 2.2) \\
BWSDS, median (range) & $9(17.0)$ \\
SGA (<-2 SDS), n (\%) & $-2.4(-5.2$ to -1.0$)$ \\
Weight wk 32 (SDS), median (range) & $34(64.2)$ \\
Weight wk 32 <-2 SDS, n (\%) & $24(45.2)$ \\
Male sex, n (\%) & $37(69.8)$ \\
Singletons, n $(\%)$ & \\
Other morbidity & $25(47.2)$ \\
ROP stage <3, n (\%) & $9(17.0)$ \\
ROP stage 3 total, n (\%) & $4(7.5)$ \\
ROP treated, n (\%) & $10(18.9)$ \\
BPD n $(\%)$ & $2(3.8)$ \\
NEC n (\%) & $6(11.3)$ \\
Brain lesion*, n (\%)
\end{tabular}

BPD, bronchopulmonary dysplasia; NEC, necrotizing enterocolitis; IVH, intraventricular hemorrhage; CP cerebral palsy.

* Definition of brain lesion: IVH $\geq$ grade III, hydrocephalus, WMD/PVL, and/or CP.

known brain lesions i.e. IVH $\geq$ grade III and/or hydrocephalus, WMD including PVL, and/or cerebral palsy. Characteristics at baseline are presented in Table 1. Visual acuity of the best eye ranged from 0.05 [ $\log$ minimum angle of resolution ( $\log$ MAR) 1.3 ] to 1.25 ( $\log$ MAR -0.1) (median 0.8, $\log$ MAR $0.1)$. Spherical equivalent of refraction ranged from +8.6 to -2.8 diopter. Four children were $>4$ diopter hyperopic.

The 13 children (seven boys and six girls) who lacked fundus photographs of sufficient quality had significantly lower serum IGF-1 levels and a lower weight at $32 \mathrm{wk}$ (SDS) than the children included in the fundus evaluation $(p=0.021$ and 0.0086 , respectively). There were no significant differences in GA and BW (SDS) between the included children and those who lacked useful photographs. Visual acuity of the best eye among the children without fundus photographs was significantly lower (median 0.4, logMAR 0.4, range: light perception to $0.9 \approx \log$ MAR 0.1 ) than in those with fundus photographs (median 0.8, $\log$ MAR 0.1, range: $0.05-1.25, \log$ MAR 1.3 to -0.1 ), $p<$ 0.001 . Their head circumference (SDS; $n=10$ ) was smaller (median -0.6 , range -3.1 to 0.3 ) than in the study group (median 0.3 , range -1.2 to 2.0 ), $p<0.001$. As judged from ophthalmoscopy and evaluation of the suboptimal photographs, only three of the 13 children had a fundus considered normal. In the remaining 10 children, large cupping of the disc was found in three, tortuous vessels in four, macular hypoplasia in three, and temporal dragging of retinal vessels after laser ablation in one child. One girl had drusen in the optic nerve diagnosed using ultrasound. Four of the children without digital optic disc analysis had brain lesions, three of them had WMD/PVL, one boy with hydrocephalus had undergone neurosurgical shunt treatment, and two had cerebral palsy. In addition, one girl had Rett syndrome, one had Bartter syndrome, and one boy had Prader-Willi syndrome. After laser ablation, one girl developed cataracts and underwent cataract extraction, and later secondary implantation of intraocular lenses. One girl had corneal clouding of unknown etiology.

Control group. The control group consisted of two groups of children, altogether 203 ( 94 boys and 109 girls), previously presented in other studies $(19,20)$. Median GA was 40 wk (range $28-43$ ). Three children were born prematurely (GA 27.6, 35.0, and $36.3 \mathrm{wk}$, respectively). Six children were born SGA $(-2.0$ to -3.3 SDS). The control children were aged 3 to $19 \mathrm{y}$. The age discrepancy between the groups was accepted because ocular fundus variables in the ages 3 to $19 \mathrm{y}$ have been found not to be age dependent (19). Visual acuity of the children ranged between 0.63 and 1.25 (logMAR 0.2 to -0.1 ; median 1.0 logMAR 0.0).

Digital image analysis of fundus photographs. The ocular fundus photographs were taken through dilated pupils and analyzed quantitatively, using a specially designed computer-assisted digital mapping system developed to focus on morphologic factors of importance for pre- and perinatal adverse events $(19,21)$. The mean value of the two eye measurements was calculated for each studied fundus structure (22). If the fundus photograph of only one eye was of sufficient quality, that eye was used $(n=44)$.

The optic disc, cup, and peripapillary crescent areas are defined by marking their outlines with a cursor (A.H.), Figure 1. The projected area is

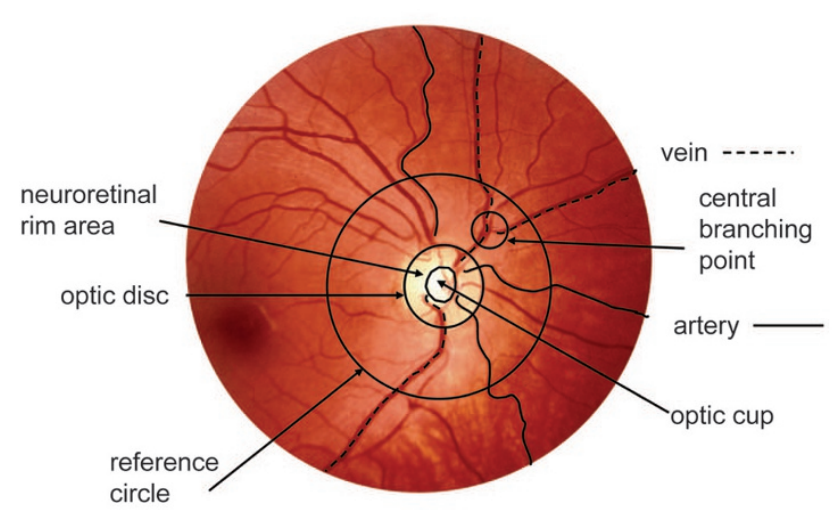

Figure 1. Drawing of the ocular fundus illustrating limits for optic disc area, cup area, and neuroretinal rim area.

automatically calculated by a computer. The optic disc is defined by the inner border surrounding the nerve tissue; care is taken not to include the white peripapillary scleral ring. The cup is defined by its contour, and its demarcation is facilitated by the course of the vessels and the pallor of the cup. The cup is easy to delineate when it appears deep and has steep boundaries. When the cup appears shallow and has sloping walls and indistinct margins, it is more difficult to delineate, and evaluation of multiple photographs from slightly different views has to be performed. The neuroretinal rim area is obtained by subtraction of the cup area from the disc area.

Ophthalmologic examination. All children had an ophthalmologic examination, including visual acuity, refraction, orthoptic status, and indirect ophthalmoscopy.

Peri- and postnatal growth variables including IGF-1 levels. SDSs for BW and weight at wk 32 were calculated for all children. To adjust for gender and differences in GA, a reference was used for calculation of SDS (23). In the neonatal period, venous blood samples $(0.5 \mathrm{~mL})$ had been taken weekly, and they were analyzed using a procedure described in the original article (16). The mean values of serum IGF-1 samples obtained during postmenstrual age from 30 to $33.9 \mathrm{wk}$ were used for analysis. At the examination at school age, head circumference (24), weight, and length (25) were measured and were expressed as SDSs.

Statistical methods. Descriptive statistics are given as mean, SD, median, and range. For comparison between two groups Fisher's nonparametric permutation test was used for continuous and ordered variables (26). Correlation was estimated with Pearson correlation coefficient and analyzed with Pitman's nonparametric permutation test (27). All tests were two sided and conducted at $5 \%$ significance level.

Ethics. The Ethics Committee at the Sahlgrenska Academy at Gothenburg University approved of the study. Written consent was received from the children's parents.

\section{RESULTS}

Optic disc morphology in preterm children versus control group. The children born preterm $(n=53)$ demonstrated smaller areas of the optic disc and neuronal rim and larger cup area than the control group $(n=203), p<0.001, p<0.001$, and $p=0.027$, respectively, Table 2 and Figure 2 .

Optic disc morphology in preterm children in relation to $B W$ and postnatal growth variables. Low BW (SDS) and weight at wk 32 (SDS) were associated with larger area of the optic cup $(r=-0.37, p=0.0083$ and $r=-0.38, p=0.0064$, respectively) as well as with a smaller neuronal rim area of the optic nerve head $(r=0.35, p=0.010$ and $r=0.31, p=$ 0.023 ), as exemplified in Figure 3. There was no correlation between sex, GA, ROP, IGF-1 or length, weight, and head circumference SDS at follow-up and the optic disc structures at school age.

Optic disc morphology in children with severe ROP and without severe ROP. Preterm children with ROP grade 3 
Table 2. Ocular fundus variables in children born very preterm and the control group

\begin{tabular}{|c|c|c|c|}
\hline Ocular fundus variable & $\begin{array}{l}\text { Preterm group } \\
\quad(\mathrm{n}=53)\end{array}$ & $\begin{array}{l}\text { Control group } \\
(\mathrm{n}=203)\end{array}$ & $\begin{array}{l}\text { Preterm group } \\
\text { versus control } \\
\text { group } \\
(p \text { value*) }\end{array}$ \\
\hline \multicolumn{4}{|l|}{ Optic disc area, $\mathrm{mm}^{2}$} \\
\hline Mean (SD) & $2.2(0.3)$ & $2.4(0.4)$ & $<0.001$ \\
\hline Median (range) & $2.2(1.3-2.7)$ & $2.3(1.6-5.3)$ & \\
\hline \multicolumn{4}{|l|}{ Cup area, $\mathrm{mm}^{2}$} \\
\hline Mean (SD) & $0.4(0.3)$ & $0.3(0.2)$ & 0.0027 \\
\hline Median (range) & $0.4(0-1.4)$ & $0.3(0-1.6)$ & \\
\hline \multicolumn{4}{|l|}{ Rim area, $\mathrm{mm}^{2}$} \\
\hline Mean (SD) & $1.7(0.4)$ & $2.1(0.4)$ & $<0.001$ \\
\hline Median (range) & $1.7(1.1-2.4)$ & $2.1(1.3-3.9)$ & \\
\hline
\end{tabular}

* Fisher's nonparametric permutation test.

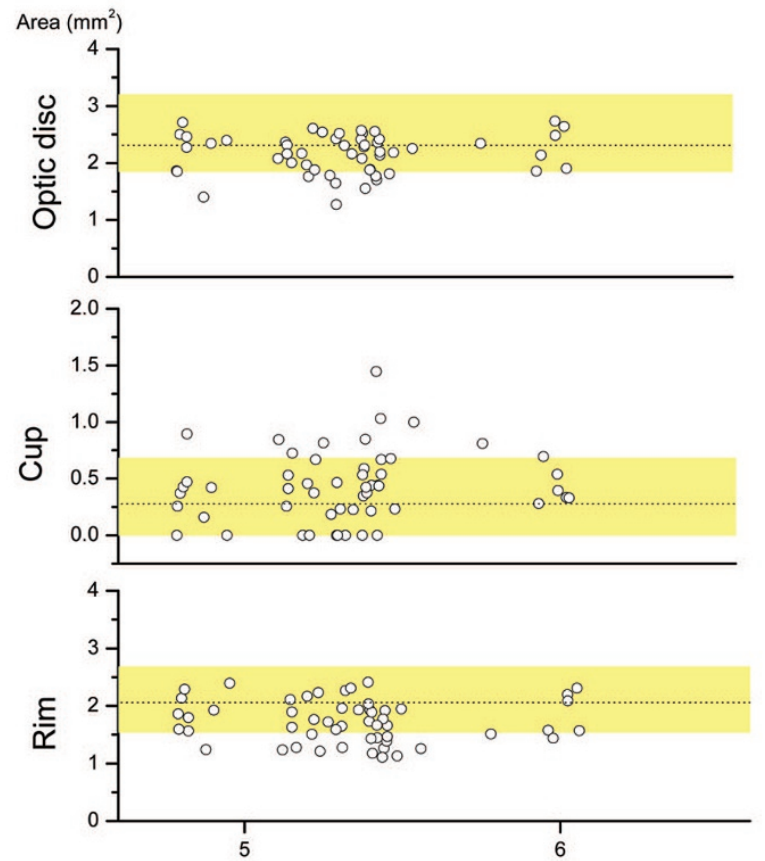

Figure 2. Area of optic disc, cup, and rim in preterm children in relation to a reference of control children. The yellow field depicts the range between the fifth and the 95th centile, and the dotted center line indicates the median of the control group.

without and with plus disease $(n=9)$ did not differ significantly from the children without severe ROP regarding the optic disc variables.

Optic disc morphology in children with and without known brain lesions. Preterm children with known brain lesions $(n=6)$ had a significantly larger cupping of the disc (mean 0.7, SD 0.2, median 0.7, range 0.5-1.0) than the preterm children without known brain lesions $(n=47)$ (mean 0.4 , SD 0.3, median 0.4, range 0-1.4), $p=0.046$. Among the children without photographs that could be analyzed, there were four children with known brain lesions, and in three of them, a large cup of the optic nerve head was noted at ophthalmoscopy according to a study protocol. However, no estimation of the optic disc size had been made.

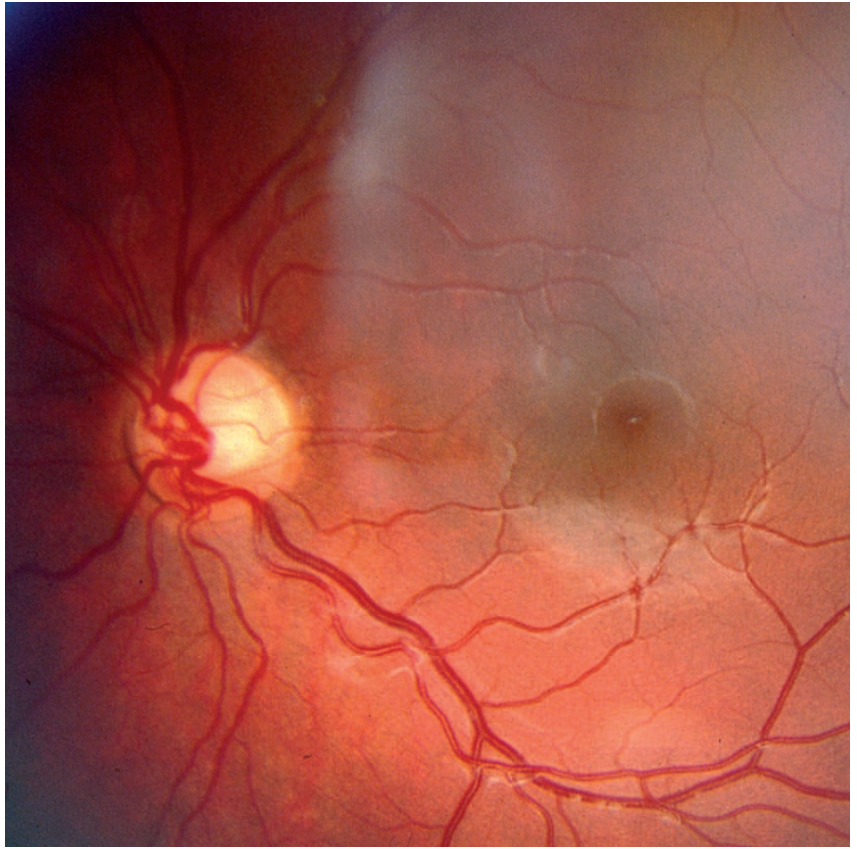

Figure 3. Fundus photograph of a boy born at gestational age $30 \mathrm{wk}$ with poor BW (BW SDS, -1.7) and perinatal weight gain (wk 32 weight SDS, $-3.1)$, and with WMD. The optic cup is large $\left(1.0 \mathrm{~mm}^{2}\right)$ and the neural rim is small $\left(1.3 \mathrm{~mm}^{2}\right)$ in comparison with the median for cup $\left(0.3 \mathrm{~mm}^{2}\right)$ and rim areas $\left(2.1 \mathrm{~mm}^{2}\right)$ for the reference group.

\section{DISCUSSION}

In this study, we found that both low SDS for BW and weight at wk 32 were associated with increased cupping and decreased neural tissue area in the optic nerve head. This finding has to our knowledge, not been reported before. In addition, we found a negative effect of preterm birth on neural tissue as exemplified by a smaller optic disc and neuronal rim area among the preterm children in comparison with the control group. This is in accordance with a previous study of optic disc variables in preterm children with the same mean GA (27 wk) (9). In another study of preterm children with a mean GA of $29 \mathrm{wk}$, no differences in optic disc variables were observed in comparison with a control group (8). Optic nerve hypoplasia is characterized by a small diameter of the optic nerve head with a reduced number of retinal ganglion cell axons, due to irreversible damage at some time before full development of the optic nerve (28). Growth of the optic disc continues after birth at term, but at a much reduced rate and the insult resulting in optic nerve hypoplasia mostly takes place early in pregnancy, but may occur later or even postnatally $(9,12,13,28)$. In a Swedish study of optic nerve hypoplasia epidemiology, children who were born preterm and/or SGA had increased risk for optic nerve hypoplasia (29). Our finding of a reduced rim area in the optic nerve head may reflect a low number of axons or a low axonal volume. We do not know whether this finding is representative for other neural tissue changes in the brain of the children born preterm. High frequency of neurologic morbidity has been reported for children with a BW $<1500 \mathrm{~g}, \sim 10 \%$ have cerebral palsy, and $\sim 50 \%$ have cognitive or behavioral deficits $(4,30,31)$. In our study group, $90 \%$ of the preterm children had a BW $<1500 \mathrm{~g}$. 
Poor early growth was common as reflected in an increase in frequency of weight SDS $<-2$ from $17 \%$ at birth to $64 \%$ at $32 \mathrm{wk}$.

The importance of early growth in preterm infants with BW $<1000 \mathrm{~g}$ was also reported in a study where higher rate of growth and weight gain from birth to discharge was associated with lower incidence of cerebral palsy and subnormal mental development index as well as neurodevelopmental impairment (32).

In this study, we found no significant correlation between serum levels of IGF-1 during gestational wk 30 to 33 and ocular fundus morphology. Fundus photography demands cooperation, concentration, and fixation, and it is not surprising that a majority of the 13 children who lacked fundus photographs were more disabled and had significantly lower serum IGF-1 levels than the children with fundus photographs. Four of these 13 children had known brain lesions and three of them had large optic cups at ophthalmoscopy. If we had received photographs of sufficient quality from all the children, the results might have been different. Thus, we cannot exclude an influence of IGF-1 in early optic nerve development.

IGF-1 is an important somatic growth factor, which promotes brain development, angiogenesis in the brain, and protection of neural tissue damage $(33,34)$. Injury to periventricular white matter (35) and corpus callosum (36) has been linked to injury to oligodendrocyte precursors, which are important for myelination (31). Lin et al. (37) showed that IGF-1 protects oligodendrocyte progenitor cells in the neonatal rat brain.

It is known that IGF-1 serum levels fall rapidly after preterm birth (38). In utero the IGF-1 levels rise during the third trimester and children with poor BW and poor weight gain have lower levels of IGF-1 (39-41). IGF-1 is related to GA, BW, and nutrition. A recent study reported that a long duration of low levels of serum IGF-1 was associated not only with ROP and poor head circumference (17) but also with increased frequency of other morbidities in premature infants, such as IVH, necrotizing enterocolitis, and bronchopulmonary dysplasia (42). A strong correlation between postnatal IGF-I levels and weight development $(41,43)$ has earlier been shown. Our finding that poor postnatal weight development was associated with later optic nerve morphology may thus in part be explained by a reduced source of factors promoting neural growth in these infants.

In this study, no associations between the variables weight, length, or head circumference at school age and optic nerve morphology were noted.

In conclusion, as previously demonstrated, preterm birth is associated with changes in the neural tissue of the optic nerve head. The association found between both low weight at birth and poor early growth and later optic nerve morphology indicates that early weight gain is important for neural development in preterm children.

Acknowledgments. We thank the staff at the Department of Ophthalmology, especially Lena Kjellberg and Birgitta Melander for their practical help with the patients, and Chatarina
Löfqvist, PhD, for analyses of neonatal data and Eva Engström $\mathrm{MD}, \mathrm{PhD}$, and Anne Rosenkvist, study nurse at the Neonatology Department for collection of neonatal data.

\section{REFERENCES}

1. Hoyt CS 2007 Brain injury and the eye. Eye 21:1285-1289

2. Woodward LJ, Anderson PJ, Austin NC, Howard K, Inder TE 2006 Neonatal MRI to predict neurodevelopmental outcomes in preterm infants. N Engl J Med 355:685-694

3. Dyet LE, Kennea N, Counsell SJ, Maalouf EF, Ajayi-Obe M, Duggan PJ, Harrison M, Allsop JM, Hajnal J, Herlihy AH, Edwards B, Laroche S, Cowan FM, Rutherford MA, Edwards AD 2006 Natural history of brain lesions in extremely preterm infants studied with serial magnetic resonance imaging from birth and neurodevelopmental assessment. Pediatrics 118:536-548

4. Volpe JJ 2003 Cerebral white matter injury of the premature infant-more common than you think. Pediatrics 112:176-180

5. Hard AL, Niklasson A, Svensson E, Hellstrom A 2000 Visual function in schoolaged children born before 29 weeks of gestation: a population-based study. Dev Med Child Neurol 42:100-105

6. Van den Broeck C, Himpens E, Vanhaesebrouck P, Calders P, Oostra A 2008 Influence of gestational age on the type of brain injury and neuromotor outcome in high-risk neonates. Eur J Pediatr 167:1005-1009

7. McLoone E, O'Keefe M, Donoghue V, McLoone S, Horgan N, Lanigan B 2006 RetCam image analysis of optic disc morphology in premature infants and its relation to ischaemic brain injury. Br J Ophthalmol 90:465-471

8. Hellstrom A, Hard AL, Chen Y, Niklasson A, Albertsson-Wikland K 1997 Ocular fundus morphology in preterm children. Influence of gestational age, birth size, perinatal morbidity, and postnatal growth. Invest Ophthalmol Vis Sci 38:1184-1192

9. Hellstrom A, Hard AL, Svensson E, Niklasson A 2000 Ocular fundus abnormalities in children born before 29 weeks of gestation: a population-based study. Eye $14: 324-329$

10. Ley D, Marsal K, Dahlgren J, Hellstrom A 2004 Abnormal retinal optic nerve morphology in young adults after intrauterine growth restriction. Pediatr Res 56:139-143

11. Hellstrom A, Dahlgren J, Marsal K, Ley D 2004 Abnormal retinal vascular morphology in young adults following intrauterine growth restriction. Pediatrics 113:e77-e80

12. Jacobson L, Hellstrom A, Flodmark O 1997 Large cups in normal-sized optic discs: a variant of optic nerve hypoplasia in children with periventricular leukomalacia. Arch Ophthalmol 115:1263-1269

13. Jacobson L, Hard AL, Svensson E, Flodmark O, Hellstrom A 2003 Optic disc morphology may reveal timing of insult in children with periventricular leucomalacia and/or periventricular haemorrhage. Br J Ophthalmol 87:1345-1349

14. Andersson S, Hellstrom A 2009 Abnormal optic disc and retinal vessels in children with surgically treated hydrocephalus. Br J Ophthalmol 93:526-530

15. Hellstrom A, Carlsson B, Niklasson A, Segnestam K, Boguszewski M, de Lacerda L, Savage M, Svensson E, Smith L, Weinberger D, Albertsson Wikland K, Laron Z 2002 IGF-I is critical for normal vascularization of the human retina. J Clin Endocrinol Metab 87:3413-3416

16. Hellstrom A, Engstrom E, Hard AL, Albertsson-Wikland K, Carlsson B, Niklasson A, Lofqvist C, Svensson E, Holm S, Ewald U, Holmstrom G, Smith LE 2003 Postnatal serum insulin-like growth factor I deficiency is associated with retinopathy of prematurity and other complications of premature birth. Pediatrics 112:10161020

17. Lofqvist C, Engstrom E, Sigurdsson J, Hard AL, Niklasson A, Ewald U, Holmstrom G, Smith LE, Hellstrom A 2006 Postnatal head growth deficit among premature infants parallels retinopathy of prematurity and insulin-like growth factor-1 deficit. Pediatrics 117:1930-1938

18. Ye P, D'Ercole AJ 2006 Insulin-like growth factor actions during development of neural stem cells and progenitors in the central nervous system. J Neurosci Res $83: 1-6$

19. Hellstrom A, Svensson E 1998 Optic disc size and retinal vessel characteristics in healthy children. Acta Ophthalmol Scand 76:260-267

20. Wikstrand MH, Niklasson A, Stromland K, Hellstrom A 2008 Abnormal vessel morphology in boys born after intracytoplasmic sperm injection. Acta Paediatr 97:1512-1517

21. Stromland K, Hellstrom A, Gustavsson T 1995 Morphometry of the optic nerve and retinal vessels in children by computer-assisted image analysis of fundus photographs. Graefes Arch Clin Exp Ophthalmol 233:150-153

22. Altman DG 1993 Construction of age-related reference centiles using absolute residuals. Stat Med 12:917-924

23. Marsal K, Persson PH, Larsen T, Lilja H, Selbing A, Sultan B 1996 Intrauterine growth curves based on ultrasonically estimated foetal weights. Acta Paediatr 85:843-848

24. Fredriks AM, van Buuren S, Burgmeijer RJ, Meulmeester JF, Beuker RJ, Brugman E, Roede MJ, Verloove-Vanhorick SP, Wit JM 2000 Continuing positive secular growth change in The Netherlands 1995-1997. Pediatr Res 47:316-323

25. Wikland KA, Luo ZC, Niklasson A, Karlberg J 2002 Swedish population-based longitudinal reference values from birth to 18 years of age for height, weight and head circumference. Acta Paediatr 91:739-754

26. Good P 2000 Permutation Tests. A Practical Guide to Resampling Methods for Testing Hypotheses. Springer Inc., New York, pp 36-37 
27. Good P 2000 Permutation Tests. A Practical Guide to Resampling Methods for Testing Hypotheses. Springer Inc., New York, pp 45-47

28. Frisen L, Holmegaard L 1978 Spectrum of optic nerve hypoplasia. Br J Ophthalmol $62: 7-15$

29. Tornqvist K, Ericsson A, Kallen B 2002 Optic nerve hypoplasia: risk factors and epidemiology. Acta Ophthalmol Scand 80:300-304

30. Saigal S, den Ouden L, Wolke D, Hoult L, Paneth N, Streiner DL, Whitaker A, Pinto-Martin J 2003 School-age outcomes in children who were extremely low birth weight from four international population-based cohorts. Pediatrics 112:943-950

31. Khwaja O, Volpe JJ 2008 Pathogenesis of cerebral white matter injury of prematurity. Arch Dis Child Fetal Neonatal Ed 93:F153-F161

32. Ehrenkranz RA, Dusick AM, Vohr BR, Wright LL, Wrage LA, Poole WK 2006 Growth in the neonatal intensive care unit influences neurodevelopmental and growth outcomes of extremely low birth weight infants. Pediatrics 117:1253-1261

33. McDonald TJ, Nijland MJ, Nathanielsz PW 2007 The insulin-like growth factor system and the fetal brain: effects of poor maternal nutrition. Rev Endocr Metab Disord 8:71-84

34. Lopez-Lopez C, LeRoith D, Torres-Aleman I 2004 Insulin-like growth factor I is required for vessel remodeling in the adult brain. Proc Natl Acad Sci USA 101:9833-9838

35. Volpe JJ 2001 Neurobiology of periventricular leukomalacia in the premature infant Pediatr Res 50:553-562

36. Johnston MV, Trescher WH, Ishida A, Nakajima W 2001 Neurobiology of hypoxicischemic injury in the developing brain. Pediatr Res 49:735-741
37. Lin S, Fan LW, Pang Y, Rhodes PG, Mitchell HJ, Cai Z 2005 IGF-1 protects oligodendrocyte progenitor cells and improves neurological functions following cerebral hypoxia-ischemia in the neonatal rat. Brain Res 1063:15-26

38. Lineham JD, Smith RM, Dahlenburg GW, King RA, Haslam RR, Stuart MC, Faull L 1986 Circulating insulin-like growth factor I levels in newborn premature and full-term infants followed longitudinally. Early Hum Dev 13:37-46

39. Langford K, Nicolaides K, Miell JP 1998 Maternal and fetal insulin-like growth factors and their binding proteins in the second and third trimesters of human pregnancy. Hum Reprod 13:1389-1393

40. Giudice LC, de Zegher F, Gargosky SE, Dsupin BA, de las Fuentes L, Crystal RA Hintz RL, Rosenfeld RG 1995 Insulin-like growth factors and their binding proteins in the term and preterm human fetus and neonate with normal and extremes of intrauterine growth. J Clin Endocrinol Metab 80:1548-1555

41. Chellakooty M, Juul A, Boisen KA, Damgaard IN, Kai CM, Schmidt IM, Petersen JH, Skakkebaek NE, Main KM 2006 A prospective study of serum insulin-like growth factor I (IGF-I) and IGF-binding protein-3 in 942 healthy infants: associations with birth weight, gender, growth velocity, and breastfeeding. J Clin Endocrinol Metab 91:820-826

42. Lofqvist C, Andersson E, Sigurdsson J, Engstrom E, Hard AL, Niklasson A, Smith LE, Hellstrom A 2006 Longitudinal postnatal weight and insulin-like growth factor I measurements in the prediction of retinopathy of prematurity. Arch Ophthalmol 124:1711-1718

43. Ong K, Kratzsch J, Kiess W, Dunger D 2002 Circulating IGF-I levels in childhood are related to both current body composition and early postnatal growth rate. J Clin Endocrinol Metab 87:1041-1044 